\title{
O TEATRO DO OPRIMIDO: DIMENSÕES POLÍTICAS E PEDAGÓGICAS EM PERSPECTIVA FREIRIANA
}

\author{
THE THEATER OF THE OPPRESSED: POLITICAL AND PEAGOGICAL \\ DIMENSIONS IN FREIRIAN PERSPECTIVE
}

\author{
Francenilza Viana de Souza Silva ${ }^{1}$ \\ Universidade Federal do Amazonas - UFAM \\ Selda Vale da Costa² \\ Universidade Federal do Amazonas - UFAM
}

\begin{abstract}
Resumo
O artigo objetiva articular a arte teatral às críticas do contexto social, a partir das concepções teóricas e metodológicas do Teatro do Oprimido, de Augusto Boal. Portanto, trata-se de um estudo teórico que analisa o método teatral que está inserido na proposta do teatro político desse autor, estruturado a partir de seis técnicas que objetivam aproximar o teatro das grandes massas. A prática do Teatro do Oprimido amplia horizontes, exercita a prática do diálogo com diferentes campos do saber. Daí a importância de se conhecerem as conexões existentes entre os fundamentos que embasam esta teoria teatral e a teoria de Paulo Freire. Conclui-se que o Teatro do Oprimido, articulado às perspectivas freiriana, é uma alternativa para que os atores sociais reflitam sobre as formas de opressões presentes na sociedade, para romper com as relações verticalizadas, autoritárias e centralizadoras, uma vez que estabelece uma relação horizontal entre elas, contribuindo para que questionem e discutam suas práticas de cidadãos.
\end{abstract}

Palavras-Chave: Teatro do Oprimido; Augusto Boal; Educação; Paulo Freire.

\section{Abstract}

The article aims to articulate theatrical art to the critical reflections of the social context, starting from the theoretical and methodological conceptions of Augusto Boal 's "Theater of the Opressed". It is a

\footnotetext{
1 Mestranda no programa de pós graduação Sociedade e Cultura na Amazônia-UFAM. Especialização em Metodologia do Ensino de Arte-UEA (2014) Possui graduação em Teatro pela Universidade do Estado do Amazonas-UEA (2014) e graduação em Educação Artística pela Universidade Federal do Amazonas-UFAM (1995). Atualmente é professor efetiva da Seduc- Cedida à Universidade do Estado do Amazonas-UEA para o Curso de Teatro.

2 Possui graduação em Ciências Sociais pela Universidade de São Paulo (1967), mestrado em Ciências Sociais pela Pontifícia Universidade Católica de São Paulo (1987) e doutorado em Ciências Sociais (Antropologia) pela Pontifícia Universidade Católica de São Paulo (1997). Atualmente é professora aposentada adjunto da Universidade Federal do Amazonas, membro permanente do Programa de Pós-Graduação Sociedade e Cultura na Amazônia.
} 
theoretical study which analyses the theatrical method inserted in the proposal of the political theater by this author, and is structured from six techniques that aims to approach the theater of the great masses. The practice of the Theater of the Oppressed broadens horizons, exercises the practice of dialogue with different fields of knowledge. Hence the importance of knowing the connections between the foundations that support this theatrical theory and Paulo Freire's theory. It is concluded that the Theater of the Oppressed, articulated to the Freirian perspectives, is an alternative for the social actors to reflect on the forms of oppression present in society, to break with the verticalized, authoritarian and centralizing relations, once it establishes a horizontal relationship among them, helping them to question and discuss their citizen practices.

Keywords: Theater of the Opressed; Augusto Boal; Education; Paulo Freire.

\section{INTRODUÇÃO}

O presente artigo objetiva articular a arte teatral às reflexões críticas do contexto social, como também estabelecer conexões da pedagogia teatral com a dimensão política na escola. Com base nas concepções teóricas e metodológicas do Teatro do Oprimido (TO), de Augusto Boal, faremos algumas reflexões sobre os fundamentos que embasam a proposta do autor e pontuaremos as articulações com o pensamento freiriano em suas formulações, além das potencialidades dela para a educação em contextos formais e não formais de ensino.

Por meio do teatro, os alunos conquistam recursos expressivos e estéticos, elaborando soluções para as situações do cotidiano. Dessa forma, a prática do Teatro do Oprimido na escola apresenta-se como atividade relevante, pois, além de sua dimensão estética, contribui para o desenvolvimento da consciência política de seus envolvidos, como processo educativo. Segundo Boal (2009, p.29-30), "pensar é organizar o conhecimento e transformá-lo em ação [...].

Consciência é a reflexão do sujeito sobre si próprio e sobre o significado dos seus atos, não apenas sobre suas consequências". Esses pontos são fundamentais nesse processo, visto que a pedagogia teatral de Boal é um campo aberto para outras interlocuções, debates e articulações possíveis.

\section{COMPREENDENDO O TEATRO DO OPRIMIDO}

O Teatro do Oprimido (TO) é um método teatral que está inserido na proposta do teatro político, estruturado a partir de seis técnicas que objetivam aproximar o teatro das grandes massas, democratizar a linguagem artística e proporcionar a interação da realidade social com a ficção para tornar o teatro uma possibilidade de crítica e transformação da sociedade. 
Com essas perspectivas, o TO surgiu a partir de experimentos e descobertas de Augusto Boal ao longo de sua trajetória artística e de vida ${ }^{3}$, as quais contribuíram para promover a reflexão dos sujeitos oprimidos, torná-los conscientes dessa realidade de opressão social, combatê-la e mudá-la.

O idealizador do TO, Augusto Pinto Boal (1913-2009), nasceu na cidade do Rio de Janeiro. Ele foi diretor teatral, autor e teórico. Escreveu sobre sua prática, formulando teorias acerca do seu trabalho, o qual ficou conhecido internacionalmente por associar teatro e contexto social.

Nessa direção, o TO e suas técnicas convergem para um único objetivo, que é conhecer e transformar a realidade social oprimida, visto que "[...] em todas as suas formas, busca sempre a transformação da sociedade no sentido da libertação dos oprimidos" (BOAL, 2013, p. 18).

Em seu livro O Teatro do oprimido e outras poéticas políticas, Boal apresenta a imagem da árvore como símbolo de seu método teatral, por representar um elemento que se encontra em constante transformação e multiplicação. O fio norteador da árvore, que se encontra na raiz, baseia-se nos princípios da "Ética da Solidariedade". Tais princípios funcionam como uma espécie de seiva que alimenta o tronco e suas copas.

Em seguida, no começo do tronco, encontra-se o que o Teatro do Oprimido pretende desenvolver - a capacidade de perceber o mundo através de todas as artes e não apenas do teatro (BOAL, 2013 p. 15), estimulando a palavra por meio da escrita; o som por meio de novas possibilidades musicais; e a imagem por meio das artes plásticas.

No tronco da árvore estão os jogos ${ }^{4}$, onde se dão os processos estéticos que estimulam a criatividade e a espontaneidade, pois possuem duas características importantes para a vida do ser humano em sociedade: regras e liberdade. Sobre os jogos Boal comenta:

[...] os jogos ajudam a desmecanização do corpo e da mente alienados às tarefas repetitivas do dia a dia [...]. Os jogos facilitam e obrigam a essa desmecanização sendo, como são, diálogos sensoriais onde, dentro da disciplina necessária, exigem a criatividade que é a sua essência (BOAL, 2013, p. 16).

Usando a representação da árvore, as suas copas correspondem as seis técnicas que compõem o TO, que são: o Teatro Imagem, o Teatro Jornal, o Arco-Íris do Desejo, o

\footnotetext{
${ }^{3}$ Boal passou pela experiência de opressão durante o período da ditadura militar no Brasil, que o levou à condição de exilado político na Argentina, Chile, França, etc. Sobre esse aspecto, ver SOUZA (2010).

${ }^{4}$ Os jogos do Teatro do Oprimido encontram-se no livro "Jogos para atores e não atores" (BOAL, 2008).
} 
Teatro Invisível, o Teatro Legislativo e o Teatro Fórum. Segundo Boal (2013), no Teatro Imagem desenvolvem-se formas de comunicação não verbal por meio da linguagem corporal. Baseia-se em utilizar o corpo como instrumento para representação da realidade com a modelação dele, consistindo em debater um problema sem o uso da palavra.

O Teatro Jornal é uma ação teatral que Boal iniciou nos anos 60, no Núcleo do Teatro Arena, e o principal objetivo era driblar a situação de opressão imposta pelo regime militar, pois a imprensa e as artes em geral eram bastante combatidas pela situação de opressão da ditadura. Essa técnica foi uma forma de denunciar tais opressões.

No Arco-Íris do Desejo são teatralizadas as situações de opressões introjetadas pelos sujeitos, que permitem tornar teatrais tais experiências. Elas estão voltadas para as experiências individuais, no entanto, não se desconecta com as demais experiências do grupo.

Outra técnica do TO descrita por Boal é o Teatro Invisível, por meio da qual são realizadas cenas teatrais, geralmente de cunho de protesto, sem que o público saiba de que se trata de teatro. Iniciado por Boal em Buenos Aires, na Argentina, quando o autor ficou exilado nos anos de 1971 a 1973, essa técnica permite realizar uma ação teatral em um lugar público, sem que se revele que se trata de ficção.

Já o Teatro Legislativo consiste na simulação de uma sessão da Assembleia Legislativa mediante a prática do Teatro Fórum, em que são entregues propostas de leis para os parlamentares. Essa técnica teve seu início em janeiro de 1993, paralelamente ao mandato de Boal de vereador da cidade do Rio de Janeiro. O objetivo do Teatro Legislativo é transformar em lei uma necessidade de uma comunidade.

Por fim, o Teatro Fórum situa-se no centro da árvore do Teatro do Oprimido e permite uma prática teatral bilateral, ou seja, permite que o espectador se torne parte do espetáculo, fazendo com que o espetáculo mude o seu roteiro original. Nas sessões do Teatro Fórum, que são conduzidas por um Curinga ${ }^{5}$, surgem ações concretas e continuadas com o objetivo de representar uma realidade de opressão. O espectador tem autonomia para modificar os rumos da história, agindo como interventor, caso queira que a história tenha outro desfecho.

Todas as vertentes do TO possuem um caráter democrático, pois permitem que em cena sejam discutidos problemas sociais, e o público atue no lugar dos atores, tornando-se "spect-atores" (BOAL, 2013).

\footnotetext{
${ }^{5}$ Nome dado ao mediador no espetáculo de Teatro Fórum. Jogos para Atores e não atores de Augusto Boal (2008).
} 
No TO, o palco é também utilizado pela plateia e não só pelo ator. Uma das indagações de Boal, que o ajudaram a pensar seu teatro enquanto metodologia, deu-se com a comparação que fez entre as propostas de um teatro revolucionário, político, reflexivo e atuante, que envolve a plateia na ação cênica, comparada ao Teatro Aristotélico, que, na perspectiva de Boal, não vislumbra tais possibilidades. Com isso, Boal quebrou paradigmas na arte teatral, as quais sempre condicionaram o espectador à passividade, sem interação com a plateia.

No que tange à temática social, as categorias teatro e política articulam-se, pois, conforme próprio autor pontua, "[...] as relações entre teatro e política é tão velha como o teatro...ou como a política. Desde Aristóteles e desde muito antes, já se colocavam os mesmos temas e argumentos que ainda hoje se discutem" (BOAL, 2013, p. 30).

No entanto, na proposta de Boal, os acontecimentos ganham vida no palco e não são mera imitação da realidade, mas são a própria realidade encenada e vivenciada pela plateia. Nesse ponto, o poder do texto sai do exclusivismo do ator, passando a ser compartilhado com o espectador.

\section{AS PERSPECTIVAS FREIRIANAS NA CONFIGURAÇÃO DO TEATRO DO OPRIMIDO}

A estética do Teatro do Oprimido baseia-se na ética da solidariedade, o que pressupõe colocar-se no lugar do outro, conhecer suas necessidades e agir para acolhêlas. Também implica levar os sujeitos oprimidos ao nível da compreensão da realidade (tomada de consciência) das injustiças sofridas, para trabalhar na perspectiva da sua superação (emancipação). Nesse sentido, aproxima-se da obra pedagógica revolucionaria de Paulo Freire (1987, p. 31-32) e da sua análise sobre essa condição:

Quem, melhor que os oprimidos, se encontrarão preparados para entender o significado terrível de uma sociedade opressora? Quem sentirá, melhor que eles, os efeitos da opressão? Quem, mais que eles, para ir compreendendo a necessidade da libertação? Libertação a que não chegarão pelo acaso, mas pela práxis de sua busca; pelo conhecimento e reconhecimento da necessidade de lutar por ela. Luta que, pela finalidade que lhe derem os oprimidos, será um ato de amor, com o qual se oporão ao desamor contido na violência dos opressores, até mesmo quando esta se revista da falsa generosidade referida.

As proposições de Boal concebem o teatro como instrumento de luta e emancipação social, inspirado em Paulo Freire, que é considerado um dos educadores mais influentes na linha da pedagogia crítica no Brasil e no mundo. O livro de Freire Pedagogia do Oprimido (escrito em 1968), completou 50 anos em 2018 e é um dos seus trabalhos mais conhecidos no mundo. Nele, Freire sintetiza seu pensamento sobre a relação de dominação na 
sociedade, que coloca os sujeitos - opressores e oprimidos - em campos opostos na luta de classes.

Nessa configuração conceitual, o pensamento marxista perpassa o sentido de sua obra, que visa à libertação dos oprimidos das amarras de um sistema opressor. Assim, sua obra é um instrumento para refletirmos sobre o ser humano no que diz respeito à busca do direito à liberdade de expressão e de escolha, pois sua humanidade encontra-se fragilizada. É exatamente esse resgate da humanização do ser que aborda o autor, quando se coloca contra um longo e injusto processo histórico de desumanização do homem, que, segundo Freire:

A desumanização, que não se verifica apenas nos que têm sua humanidade roubada, mas também, ainda que de forma diferente, nos que a roubam, é distorção da vocação do ser mais. É distorção dado ser mais. É distorção possível na história, mas não vocação histórica. $\mathrm{Na}$ verdade, se admitíssemos que a desumanização é vocação histórica dos homens nada mais teria que fazer, a não ser adotar uma atitude cínica ou de total desespero. A luta pela humanização, pelo trabalho livre, pela desalienação, pela afirmação dos homens como pessoas, como "seres para si", não teria significação. Esta somente é possível porque a desumanização, mesmo que um fato concreto na história, não é, porém, destino dado, mas resultado de uma "ordem" injusta que gera a violência dos opressores esta, o de ser menos (FREIRE, 1987, p. 30).

O autor proporciona a reflexão sobre a condição de alienação humana, que nem sempre é perceptível, visto que se camufla no processo de exploração, ofuscando a consciência para essa realidade historicamente construída e, por vezes, até naturalizada. Augusto Boal não só intitula sua obra como Teatro do Oprimido, reportando-a à de Paulo Freire, como também comunga de suas ideias e a cita em seu trabalho, como na passagem a seguir:

Freire também é um crítico mordaz da realidade à qual é confrontado, a de uma concepção "bancária" da educação onde "o professor se apresenta a seus alunos como seu 'contrário' necessário: ao considerar que a ignorância deles é total, ele justifica pela sua própria existência” (BOAL, 2013, p. 211).

Percebe-se que a luta política faz parte do contexto escolar, fruto da resistência dos movimentos sociais pelos direitos humanos fundamentais, e é um poderoso mecanismo que impede muitas vezes que nossos estudantes estejam sob o jugo da obediência e submissão.

A prática do TO possibilita ao ser humano perceber sua existência nua e crua, lutar pelos direitos para vê-los assegurados nas leis e nas práticas sociais. Quando o sujeito não tem consciência dos seus direitos e não luta pelos mesmos, a cultura da servidão se perpetua e se naturaliza, podendo até provocar sentimentos de inferioridade nos próprios 
oprimidos, ao acharem que realmente devem ser humilhados pelo fato de terem menos escolaridade, menores salários etc. Para autores como Freire e Boal, essa situação causa a alienação e desumanização. Logo, a tomada de consciência dessa realidade é que pode mudar a cultura de servidão, como afirma o Paulo Freire:

De tanto ouvirem de si mesmos que são incapazes, que não sabem nada, que não podem saber, que são enfermos, indolentes, que não produzem em virtude de tudo isto, terminam por se convencer de sua "incapacidade". Falam de si como os que não sabem e do "doutor" como o que sabe e a quem devem escutar. Os critérios de saber que lhe são impostos são os convencionais. Dentro desta visão inautêntica de si e do mundo os oprimidos se sentem como se fossem uma quase "coisa" possuída pelo opressor (FREIRE, 1987, p. 50).

Dentro do contexto do ensino do teatro, percebemos que o TO, enquanto potencialidade pedagógica, alinha-se à concepção freiriana e potencializa a ação do professor com suas várias técnicas, possibilitando ao estudante não se ver como um cidadão incapaz e subserviente, mas como um cidadão que pode contribuir para a transformação de seu contexto social. Esse aspecto da pedagogia teatral contribui para a construção de uma prática pedagógica problematizadora, possibilitando, dessa forma, atrelar o teatro ao contexto social de seus estudantes.

Observa-se que tanto a proposta da Pedagogia quanto o Teatro do Oprimido apontam saídas para desalienação do sujeito e mudanças de postura do opressor e propõem o diálogo como o grande aliado para resolução de problemas de opressão.

É por meio do diálogo que existe a possibilidade de o oprimido externar suas angústias e de o opressor ouvi-las, pois, segundo a premissa freiriana, "não é no silêncio que os homens se fazem, mas na palavra, no trabalho, na ação-reflexão" (FREIRE, 1987, p. 78).

O falar e o ouvir são virtudes que o ser humano precisa desenvolver para se reconhecer como tal e, nesse contexto, tanto oprimidos como opressores se libertam, rompendo com a polarização historicamente construída. A proximidade do Teatro do Oprimido com o pensamento freiriano dá-se em função de ambos assumirem uma postura crítica diante da vida e seus problemas.

\section{A ESTÉTICA DO TEATRO DO OPRIMIDO E REFLEXÕES SOBRE QUESTÕES EDUCACIONAIS}

O ensino do teatro propicia estudos e experiências estéticas, possibilitando ao aluno ser sujeito de sua própria aprendizagem, conhecendo desde seu corpo a seu contexto social, além de suas possibilidades de expressão e de comunicação. A prática do Teatro 
do Oprimido em contextos educacionais contribui com a transformação da educação, sendo uma alternativa para professores, estudantes e comunidade fazerem dessa linguagem artístico-pedagógica um veículo de mudança de mentalidade, transformação social e luta política.

Na educação brasileira, o espaço para o ensino das Artes, onde o teatro se insere, historicamente ocupa(va) um lugar periférico, quando comparado às disciplinas como Matemática e Língua Portuguesa, por exemplo. Em 1971, com a lei ํㅜ 5.692, que alterou a Lei de Diretrizes e Bases da Educação Nacional, nº 4.024/61, a então disciplina Educação Artística trouxe a perspectiva da polivalência no ensino de arte, tendo um professor para trabalhar com todas as áreas das artes.

As escolas de arte dramática foram censuradas pelo Regime Militar, pois eram julgadas perigosas, a ponto de seus conteúdos serem encaminhados ao Departamento de Censura Federal, como comenta Japiassu (2012, p. 63): “Em 1968, essas escolas de arte dramática foram invadidas e fechadas e muitos professores aposentados com base no Ato Institucional $n^{\circ} 5$ e na lei de segurança nacional".

Atualmente, o ensino da arte inclui o teatro como uma das linguagens artísticas na Educação Básica e, dessa forma, o teatro pode se tornar uma realidade nas escolas. As aulas de teatro e, principalmente de teatro político, possibilitam ao estudante uma nova leitura de mundo, uma desmecanização da mente por meio de várias práticas de jogos e exercícios teatrais do TO.

Ao afirmar que "felizmente, o teatro aristotélico não é a única maneira de se fazer teatro" (BOAL, 2013, p. 31) ${ }^{6}$, por mascarar a crítica social que está por trás da cena e querer do espectador a anestesia da catarse, essa forma de representação se assemelha a esse sistema de ensino, que mascara uma realidade social, impedindo que seu principal protagonista (que deve ser o espectador, o cidadão) atinja o nível de consciência política e emancipação suficientes para sair da alienação.

Portanto, do ponto de vista do ensino de Arte, o TO é um excelente recurso metodológico para que seus praticantes exercitem uma postura política de entendimento e resistência frente às questões educacionais. Com suas várias técnicas, possibilita aos sujeitos sair da alienação e lutar pela transformação da realidade de opressão social.

Embora Boal não tenha escrito diretamente sobre educação, as bases freirianas de sua obra o aproximam do universo educacional, e a utilização das técnicas e,

\footnotetext{
${ }^{6}$ O Teatro Aristotélico é a forma de teatro clássico, que propõe a poesia em detrimento da política. Não possui
} unidades de tempo, ação e lugar. Provoca a Catarse no espectador. Estrutura mantida até hoje. 
principalmente, da estética do Teatro do Oprimido, ao serem trabalhadas nos mais variados contextos educacionais, potencializam uma vivência teatral comprometida com a autonomia e com sua atuação cidadã politizada.

\section{CONSIDERAÇÕES FINAIS}

Boal defende um teatro democrático, onde todos possam ter acesso. A partir de suas ideias, defendemos que devam existir espaços para o ensino do teatro nas escolas, não só os físicos, mas, sobretudo, os simbólicos, pois se trata de uma ação que possibilita a quem o execute ter liberdade de expressão, autonomia para modificar os rumos da história ou compreendê-la, aspectos que se articulam ao pensamento de Freire.

O Teatro do Oprimido é uma alternativa para que os atores sociais reflitam sobre as formas de opressões presentes na sociedade, para romper com as relações verticalizadas, autoritárias e centralizadoras, uma vez que estabelece uma relação horizontal entre elas, contribuindo para que questionem e discutam suas práticas de cidadãos.

Em tempos como estes, onde vivemos no campo político tantos retrocessos, com ataques ao pensamento livre, à arte e aos alicerces democráticos, ainda pouco sedimentados em nossa sociedade, resgatar as perspectivas de Boal e Freire, em seus chamados para a tomada de consciência dos oprimidos, traduz-se em uma pauta que se renova.

A prática do Teatro do Oprimido amplia horizontes, exercita a prática do diálogo com diferentes campos do saber. A cidadania, para Boal, reside na capacidade de não apenas vivermos em sociedade, mas de poder transformá-la. A primeira transformação vem do próprio indivíduo, pois precisa se sentir parte da natureza e não superior a ela, para depois ver o mundo e o outro com respeito.

Acreditamos que a escola possa ser esse lugar, onde possamos refletir sobre o contexto social e se dispor ao outro, e a dimensão política do TO contribui para isso.

\section{REFERÊNCIAS}

BOAL, Augusto. Teatro do oprimido e outras poéticas políticas. São Paulo: Cosac Naify, 2013.

BOAL, Augusto. A estética do oprimido. Rio de Janeiro: Garamond, 2009.

BOAL, Augusto. Jogos para atores e não atores. Rio de Janeiro: Civilização Brasileira, 2008.

FREIRE, Paulo. Pedagogia do oprimido. 17. ed. Rio de Janeiro: Paz e Terra, 1987. 
JAPIASSU, Ricardo. Metodologia do ensino de teatro. 9. ed. Campinas: Papiros, 2012. SOUZA, Clara de Andrade. Exílio: memória ou esquecimento? Um olhar sobre Augusto Boal. Palimpsesto, o 10, ano 9, 2010.2 Disponível em: http://www.pgletras.ueri.br/palimpsesto/num10/dossie/palimpsesto10 dossie05.pdf. Acesso em 9/8/2018.

Artigo recebido em: 05 de outubro de 2019 Aceito para publicação em: 20 de dezembro de 2020 